\title{
Autosomal dominant spastic paraplegia type 3
}

INSERM

\section{Source}

INSERM. (1999). Orphanet: an online rare disease and orphan drug data base. Autosomal dominant spastic paraplegia type 3. ORPHA:100984

Autosomal dominant spastic paraplegia type 3 is a rare, pure or complex subtype of hereditary spastic paraplegia, with highly variable phenotype, typically characterized by childhood-onset of minimally progressive, bilateral, mainly symmetric lower limb spasticity and weakness, associated with pes cavus, diminished vibration sense, sphincter disturbances and/or urinary bladder hyperactivity. Additional associated manifestations may include scoliosis, mild intellectual disability, optic atrophy, axonal motor neuropathy and/or distal amyotrophy. 